\title{
Preventing psychosocial risks at work: An evaluation study of labour inspectorate interventions
}

\author{
Rafaël Weissbrodt $^{\mathrm{a}, *}$, Marc Arial ${ }^{\mathrm{a}}$, Maggie Graf ${ }^{\mathrm{a}}$, Samuel Iff ${ }^{\mathrm{a}}$, David Giauque \\ a State Secretariat for Economic Affairs (SECO), Labour Directorate, Working Conditions, Labour and Health, Holzikofenweg 36, CH-3003 Bern, Switzerland \\ ${ }^{\mathrm{b}}$ University of Lausanne, Institute of Political, Historical and International Studies, CH-1015 Lausanne, Switzerland
}

\section{A R T I C L E I N F O}

\section{Keywords:}

Inspection

Intervention

Psychosocial work environment

Psychosocial risk

Assessment

Outcome

\begin{abstract}
A B S T R A C T
Workplace responses to labour inspectorate interventions regarding psychosocial risks at work are not well known. This study aimed to assess the effects of inspection visits at company level. A survey was conducted in two groups of companies. In one group, companies were visited by a labour inspector some days after the survey, and in the other group, not. The survey was repeated one year later in both groups. It relied on a structured phone interview with the person within the company who best knew about occupational health and safety. We collected information about health and safety management, worker participation, as well as ability, willingness and measures for the prevention of psychosocial risks. Two kinds of prevention measures were distinguished: specific psychosocial risk management measures on one side, and more general improvements of working conditions on the other side. 185 companies with an inspection visit and 161 companies without took part in the study. The results were encouraging, since inspected companies improved their management of health and safety, increased their ability in psychosocial issues, and demonstrated a stronger willingness to act. To a lesser extent, they implemented specific psychosocial risk management measures. However, visits did not lead to improvements regarding scores for employee participation or general improvements of working conditions, such as work organisation, working schedules or staffing levels. A further step for regulatory initiatives would be to emphasise more strongly the need for a prevention approach grounded in the assessment and improvement of job designs, content and organisation.
\end{abstract}

\section{Introduction}

In the last two decades, a growing number of health and safety authorities have developed public policies and programmes to prevent psychosocial risks at work (PSRs) such as occupational stress, burn out, harassment or aggression (Lippel and Quinlan, 2011). These risks have been defined as "those aspects of the design and management of work, and its social and organisational contexts, that have the potential for causing psychological or physical harm" (Cox et al., 2003, p. 195). Several publications have described regulatory interventions aimed at controlling these risks (Leka et al., 2015a; Lippel and Quinlan, 2011; Weissbrodt and Giauque, 2017). Labour inspectorates play a central role in informing, advising and monitoring workplaces. However, due to their complexity, PSRs remain a challenge for companies and regulating bodies, and authors have observed a gap between policy and practice (Bøgehus Rasmussen et al., 2011; Hansen et al., 2015; Leka et al., 2015a; Lippel and Quinlan, 2011). There are indications that inspectors are quite successful at convincing employers during inspection visits, but that prevention policies have not really improved the psychosocial working environment at a more macro level. A possible explanation might be that inspectors are only able to inspect a fraction of workplaces, and perhaps not the worst ones (Langenhan et al., 2013; Leka et al., 2011; Weissbrodt and Giauque, 2017; Zoni and Lucchini, 2012).

Judgements about the effectiveness of inspection visits in this field have usually relied upon qualitative research or narrative reviews. A recent systematic literature review (Weissbrodt and Giauque, 2017) found no published research measuring labour inspection outcomes - in terms of PSR prevention - in an experimental or quasi-experimental setting. Several authors have encouraged researchers to develop evaluation studies of occupational health and safety (OHS) interventions, in order to provide sound bases for practice, inform the development of standards and regulations, and avoid wasting time and money on ineffective interventions (Landry, 2008; Lindblom and Hansson, 2004;

\footnotetext{
* Corresponding author at: Chemin de l'Hôpital 12, CH-1870 Monthey, Switzerland.

E-mail addresses: grweissbrodt@bluewin.ch (R. Weissbrodt), marc.arial@seco.admin.ch (M. Arial), maggie.graf@seco.admin.ch (M. Graf), samuel.iff@seco.admin.ch (S. Iff), david.giauque@unil.ch (D. Giauque).
} 
Robson et al., 2001; Shannon et al., 1999). As labour inspectorates have limited resources (Weil, 2008), there is a strong demand from regulatory agencies to assess their inspection outcomes. Therefore, a quantitative assessment of inspection effectiveness in improving PSR management at company level would be both innovative and useful for public policy; this was the aim of the study.

\section{Conceptual model and hypotheses}

Science makes the invisible, visible. This catchphrase applies well to evaluation research in occupational health and safety. Indeed, OHS interventions generally do not produce self-explanatory effects. Prevention is much about avoiding the occurrence of something visible an accident, an occupational disease or a work-related health disorder. Tompa et al. (2016) and Robson et al. (2007) have published comprehensive reviews of studies addressing the prevention of workplace injuries through regulatory enforcement or OHS management systems. Some authors, such as Bourbonnais et al. (2011), have also conducted research to evaluate the final impacts of organisational stress prevention programmes, for instance by using self-assessed health questionnaires among employees. However, because of the "wicked" nature of psychosocial risks (Jespersen et al., 2016), it is most difficult to establish causal relationships between interventions and health outcomes. This is especially true for regulatory inspection visits, which occur over a few hours, while organisational stress prevention programmes may last several months.

In this context, Hansen et al. (2015) suggested an "impact ladder" to define the expected outcomes of working environment inspections and to measure their actual achievements. It includes seven steps: (1) changes in knowledge at the workplaces, (2) changes in attitudes, (3) improvements in the enterprises' working environment efforts, (4) safer production technology and work processes, (5) reduction in exposures, (6) reduction in the rate of accidents and work-related diseases, and (7) improved health. The authors have recommended the labour inspectorates to concentrate their impact measurements on intermediate outcomes (steps 1-5), as the causal relationships at steps 6-7 are very complex. In the same vein, Robson et al. (2001) have explained that safety interventions occur at three levels of a workplace safety system: the organisation of safety management, the technical subsystem and the human sub-system. Regulatory interventions on psychosocial risks can affect these three layers. They can result in formal policies, procedures or structures; in an improved work organisation, design or environment; and in stronger ability, knowledge or motivation among managers and employees.

Because of this multiplicity of outcome levels, developing a conceptual model may help clarify what the intervention is supposed to change, and how (Kompier and Aust, 2016; Robson et al., 2001; Shannon et al., 1999). This study uses a simple model based on a realistic evaluation approach (Pawson, 2006); it is presented in Fig. 1. It focusses on planned proactive company visits by labour inspectors to assess the quality of the workplace OHS management system. This is consistent with the practice observed in advanced liberal economies (Walters et al., 2011). Since the late 1980s, inspectorates have strongly focussed on the monitoring of OHS systems within workplaces. They check if processes are in place to ensure the detection and prevention of occupational hazards; this strategy has shown some success, at least in Nordic countries (Walters et al., 2011). In response to the increasing importance of psychosocial issues, the mainstream approach has been to cover them by broadening the spectrum of regulatory OHS management systems. Indeed, previous research has shown the prevention of PSRs to be closely related to OHS management (EU-OSHA, 2012b; Jain, 2011). Consequently, labour inspectors mostly investigate psychosocial issues by assessing their inclusion in workplace policies and procedures (Toukas et al., 2015). Because of this mechanism of action, one of the expected outcomes of the campaign is a better OHS management. Beside this process approach, literature often describes "enlightenment" (i.e. educating, advising and persuading) as another generative mechanism (Bøgehus Rasmussen et al., 2011; Quinlan et al., 2009; Saksvik et al., 2007; SLIC, 2012; Walters et al., 2011). There is some evidence of positive results of this approach on employer awareness, documentation of OHS activities, assessment of risk factors, workplace ability to prevent PSRs, and implementation of prevention measures (Hansen et al., 2015; SLIC, 2012; Walters et al., 2011). The conceptual model also suggests an effect of inspection on worker participation. Participation is an important precondition for effective prevention of PSRs (Kompier, 2004; Walters, 2011). OHS management systems must provide consultation and information rights to employees; it belongs to the inspectors' task to verify that these requirements are met (Walters, 2004).

The model also includes elements of context. According to the realistic evaluation approach, a given programme can generate different results, depending on the circumstances (Pawson and ManzanoSantaella, 2012). Factors interacting with the inspection process may relate to workplace structure. There is a positive relationship between company size and prevention efforts (EU-OSHA, 2012b; Hasle et al., 2014; Jain, 2011; Pinder et al., 2016); besides, manufacturing and construction firms have less developed prevention practices than service companies (EU-OSHA, 2012b). Economic situation at company level could also be of importance; this parameter was kept for exploratory purposes. Other factors relating to the broader context might play a role and are listed in Fig. 1 (Bruhn and Frick, 2011; Hansen et al., 2015; Johnstone et al., 2011; Leka et al., 2015b); they were investigated in other parts of this study, in order to better interpret the results. Based on the model, the following research hypotheses were studied:

\section{H1. Inspection visits result in an improvement in OHS management.}

H2. Inspection visits increase worker participation within workplaces.

H3. Inspection visits increase employer willingness to prevent PSRs.

H4. Inspection visits increase employer ability to deal with PSRs.

H5. Inspection visits induce firms to implement measures to prevent PSRs.

H6. Inspection visits have most effect in large service companies.

We tested the hypotheses by means of a quasi-experimental design, described in the next section.

\section{Study population and methods}

\subsection{Study design and sample selection}

From 2014 to 2018, the Swiss cantonal labour inspectorates participated in an inspection campaign on PSRs coordinated by the federal government (State Secretariat for Economic Affairs, SECO). The SECO organised specific training courses for inspectors, produced guidance (brochures, leaflets, website and tools), and participated in several events to heighten awareness among inspectors, employers and OHS specialists. Inspectors were requested to address PSRs during their workplace visits; all branches were concerned, with a special focus on service companies and health care. Based on internal documents of the SECO, Box 1 describes the programme theory (Kompier and Aust, 2016), i.e. the way the campaign was expected to work and produce its outcomes.

A pre- and post-intervention design with a control group was used to assess the outcomes. Two questionnaire surveys were conducted at a one-year interval to compare the evolution of two groups of companies. The intervention group was made up of firms in which labour inspectors conducted a systematic visit. For approximately one year, the inspectors informed the investigators in advance of every planned visit so that the company could be contacted beforehand. The control group was randomly selected from the Swiss business and enterprise register 


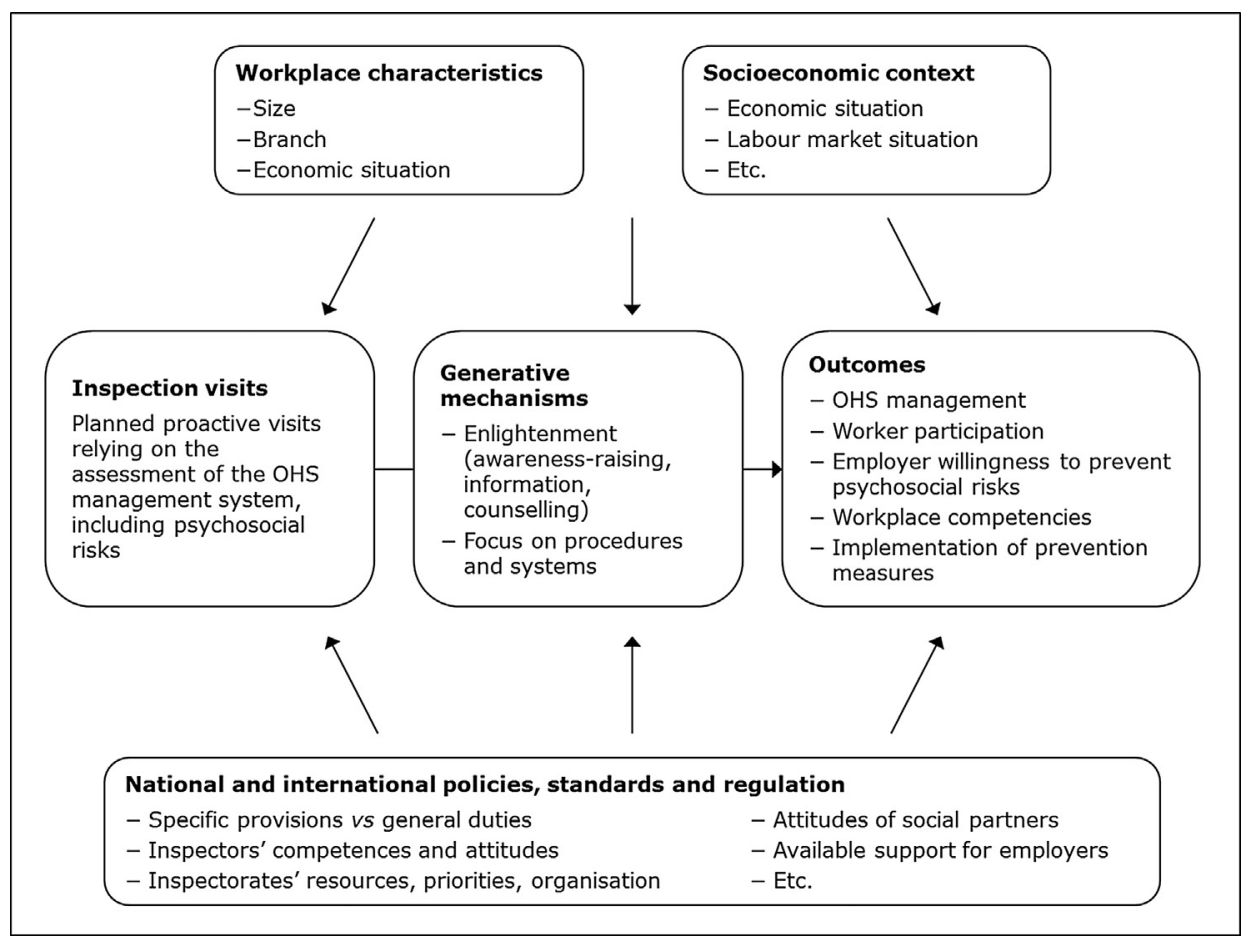

Fig. 1. Conceptual model.

and stratified by language region, size, sector and structure (single $v s$ multi-branch companies), to match the constitution of the intervention group as closely as possible. No inspection was done in these companies during the investigation period. The questionnaire was answered by the person within the company who best knew about OHS. This person could answer either by structured phone interview or by completing a written questionnaire. Data were managed using REDCap electronic data capture tools (Harris et al., 2009). Approval by an ethics committee was not necessary, since no personal data was collected and the SECO has a legal prerogative to gather information on workplaces.

\subsection{Survey questionnaire}

The content of the questionnaire and the design of scales by means of factor analyses have been described in a previous publication (Weissbrodt et al., 2018). Based on the hypotheses, 53 variables were kept for the analyses, covering OHS management, worker participation, PSR prevention (willingness, ability, measures in place), company characteristics and, for the inspected firms, perception of the visit by the respondent. Missing values were dropped; they were less than $0.3 \%$, except for one item (1.2\%).

Data collection in the intervention group was complemented by gathering information on the inspection process, in order to explain how and why inspection visits produced the measured outcomes. After each visit, we sent a short on-line survey to the inspector so as to determine whether he or she had actually addressed psychosocial issues during the visit, and what type of action, if any, he or she had required. Qualitative data was finally collected by participating in inspection visits as observers and conducting workshops with inspectors, in order to better interpret the outcomes.

Box 1

Programme theory.

Inspectors approach PSRs as part of their OHS system audits. They inform and sensitize companies on the nature and consequences of PSRs, and on the legal duty to prevent them. Their intervention must lead employers to implement measures to protect their employees. Inspectors enable their interlocutors to develop a basic understanding of PSRs, and provide them with information on how to address these risks. The main objective is to persuade them of the need to act, rather than prescribe specific measures. However, where there are clear signs of the existence of risks and managers do not perceive the necessity to prevent them, it may be necessary to compel firms to implement measures or to seek expert advice.

In order to get an idea of the situation within the workplaces, inspectors ask employers about their commitment to their employees' health. Through open-ended questions, they monitor what processes and measures are in place to protect the staff from violations of their personal integrity (discrimination, harassment, etc.) and to ensure that work demands are commensurate with employees' abilities (prevention of stress, overwork or monotony). They examine the extent to which companies integrate PSRs into their OHS management system. They identify risk indicators, e.g. by discussing with the employer, reviewing human resources management data, visiting premises and interviewing employees.

Employers are the ones responsible for assessing risk factors. Inspectors request such an assessment when they observe multiple cues of psychosocial problems. They advise the company by showing how to identify PSRs and take the first preventive measures; they indicate which specialised services can provide support. However, they do not make a risk assessment themselves, nor do they act as mediators in the event of a dispute. 


\subsection{Statistical analyses}

All analyses were conducted with Stata 14 (StataCorp, 2015). In a first step, inspected and non-inspected firms were compared, at baseline and one year later, using $\mathrm{Chi}^{2}$ and nonparametric tests on the equality of medians. In a second step, regression models were built to assess the effectiveness of the inspection visits. The dependent variables were the scores from the second survey. The predictors were the interaction terms between visit, economic sector (secondary $v s$ tertiary) and company size (less than 100 vs $100+$ employees); economic situation was excluded from the predictors due to p-values larger than 0.25 in the univariate models (Hosmer et al., 2013). The tertiary sector, uninspected workplaces with less than 100 employees served as the comparison basis. The score at baseline was also introduced as a predictor in order to control for initial differences between the two groups. Statistical power, absence of multicollinearity and normality of residuals were checked-on. We used a robust regression method (Stata's command robreg), the robust coefficient of determination $\mathrm{R}^{2}(\mathrm{w})$ (Jann, 2010; Renaud and Victoria-Feser, 2010) and White's heteroscedasticityconsistent standard errors. Finally, multiple regression analyses were undertaken to predict the influence of the inspection visits on the implementation of an array of specific prevention measures after one year, controlling for their implementation at baseline (Stata's command regress).

\section{Results}

185 inspected and 161 non-inspected companies were compared in a one-year interval. Fig. 2 depicts the process for the constitution of both groups. There was no evidence for differences between groups according to branch, size and economic situation.

Inspectors reported addressing PSRs in $97.2 \%$ of the workplace visits announced to the investigators. They required prevention measures against PSRs in $49.4 \%$ of them. About one third (34.2\%) of the company respondents acknowledged that the visits had led to the implementation of measures, and $47.2 \%$ found that it had increased their knowledge. The factor analyses resulted in six single-factor scales (Table 1). At baseline, the inspected firms showed higher medians than the non-inspected on three scales. After one year, all median scores except for the improvement of working conditions - had increased and were higher for the inspected companies.

Table 2 presents the results of the regression analyses. The inspected large companies from the tertiary sector improved on almost every scale; they had the strongest increases of all groups on the specific PSR management and on the perceived ability for prevention. Overall, inspection visits particularly improved OHS management practices and perceived workplace ability. Some non-inspected categories also showed improvements, especially on OHS management practices in the large companies from the secondary sector, and on the perceived ability for the large tertiary firms. The willingness to prevent PSRs increased only in the inspected companies. By contrast, almost no effect of inspection on worker participation was found. An effect of inspection on specific PSR management practice was found only in the large tertiary companies, but large non-inspected secondary firms also improved to some extent. Finally, there was no measurable effect on the general improvement of working conditions.

Multiple regression analyses on the single prevention measures showed that inspection had statistically significant effects on the following items: charter or rules on PSRs, role clarity for PSR management ( $p<.001)$; changes to the contractual requirements of some employees to reduce stress $(\mathrm{p}<.01)$; confidential counselling, conflict resolution procedure, and recording of working hours ( $\mathrm{p}<.05)$. These items all belong to the specific PSR management scale, with the exception of the changes to the contractual requirements (improvement of working conditions scale) and the recording of working hours (not included in a scale).
Overall, the analyses support the hypotheses H1 (effect on OHS management), H3 (effect on employer willingness to prevent PSRs), H4 (effect on perceived workplace ability) and H6 (strongest effect in large service companies). Data only partially supports hypothesis H5 (effect on prevention measures), and does not support hypothesis $\mathrm{H} 2$ (effect on worker participation).

\section{Discussion}

\subsection{Interpretation of the findings}

This study shows significant effects of inspection visits on several dimensions of PSR prevention. The inspected companies improved their OHS management, perceived ability in psychosocial issues, and willingness to act. Inspection also led to the implementation of several psychosocial risk management measures. The effects were most visible in tertiary companies with more than 100 employees, then in smaller tertiary firms, and finally in secondary sector workplaces regardless of their size.

The positive impact of inspection visits on OHS management is an interesting finding against the backdrop of contrasting evidence from previous studies. According to several reviews, case studies have demonstrated the importance of regulatory inspections for systematic approaches to health and safety; however, the evidence that they effectively produce improvements and achieve an acceptable level of protection for workers remains insubstantial (Robson et al., 2007; Walters et al., 2011). Nevertheless, Walters et al. (2011) have also reported on positive experiences in Nordic countries. Promotional strategies aimed at improving OHS management have led to an acceptance and implementation of these systems, even if it has not always been as substantial as expected. Our results seem to show a similar tendency in Switzerland, with inspection visits tending to strengthen factors typically related to OHS management: mainly management review, documentation, implementation of some measures, and hazard identification. The currently dominant view on the best prevention of PSRs is to integrate them into a comprehensive OHS management system (Hansen et al., 2015; Johnstone et al., 2011). If true, these improved management processes should also lead to an improved prevention of PSRs. In this study, inspections led to a better knowledge of prevention measures, improved informing of employees, more frequent statements that measures were in place, and more regular hiring of experts. This illustrates and to some extent supports the often described "enlightenment" approach of labour inspection (Bruhn, 2006, 2009; Frick, 2014; Lippel and Quinlan, 2011; Quinlan et al., 2009; Walters et al., 2011). Qualitative observations have confirmed that the dissemination of leaflets, guidance and electronic resources assume an important place in the inspection activity. Furthermore, several survey respondents expressed the desire to receive more branch-specific information detailing the steps to be taken.

Inspections resulted in a broader implementation of some specific prevention measures, principally related to formal endeavours and individual support. This is consistent with qualitative observations. A large proportion of the measures advocated by inspectors are processoriented (e.g. a written commitment by the employer or procedures in case of harassment), or aim at supporting individuals. There has been a considerable market development for persons providing confidential support to employees, after the Swiss Federal Court confirmed the right of inspectors to require it in specific instances ${ }^{1}$. In the absence of specific legal provisions on psychosocial risks, the judgment has tended to focus attention on this secondary prevention measure. This may have reinforced a pre-existing tendency for companies to favour assistance programmes rather than primary prevention (Mellor et al., 2011). Indeed, the results showed no statistically significant effect of inspection

\footnotetext{
${ }^{1}$ Federal Court judgment ATF 2C_462/2011
} 


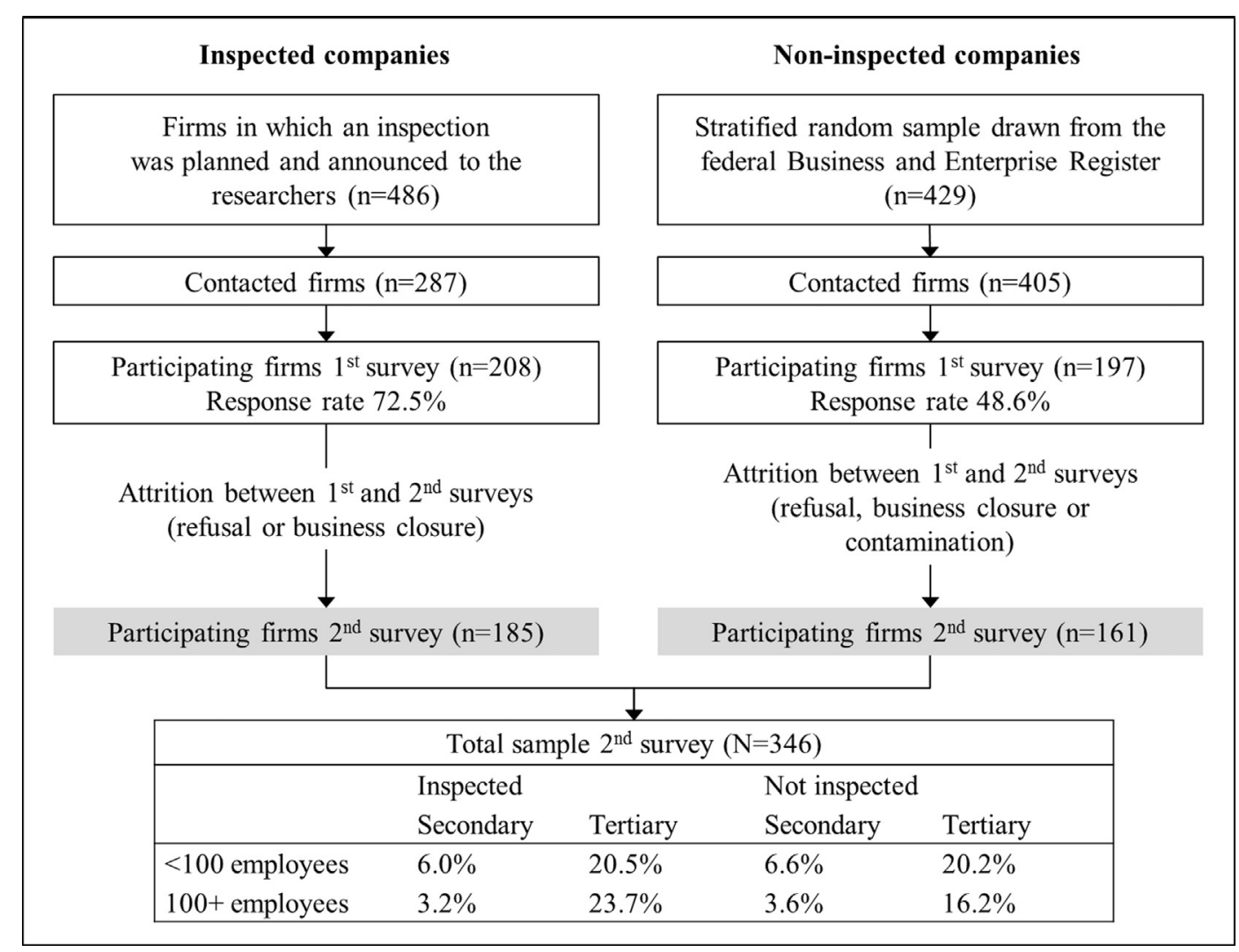

Fig. 2. Sample constitution.

on work organisation, working time arrangements, staffing levels, or improvement of work tools or the working environment. There was one exception concerning the changes to the contractual requirements of some employees to reduce stress; however, this also falls under the category of individual support. Interestingly, visits nevertheless had a positive impact on the recording of working hours. During the study, there was a change in the legal requirements to record working hours, following heated political debate; inspectors have particularly monitored this duty. This item was not part of our prevention scales; nevertheless, respecting breaks and the maximum authorised working hours obviously contributes to occupational health.

The lack of improvement concerning work organisation is consistent with other studies, which showed that employers often tend to perceive PSRs as individual problems requiring support measures (Frick, 2014; Mellor et al., 2011). To fully attain the desired effect of reducing PSRs, government initiatives should encourage employers towards more primary prevention in future. Both risk-factor based inspections (Hansen et al., 2015) and the organisational ergonomics approach focussing on quality work (Petit and Dugué, 2012) could constitute appropriate sources of inspiration. Directing attention to practical dimensions of the psychosocial working environment rather than towards processes and systems may be more instructive to employers, particularly in small and medium enterprises.

The lack of a significant effect of inspection visits on worker participation is of concern, since participation seems to be an important condition for effective prevention and inspection (Bruhn, 2006; Dollard and Neser, 2013; Hansen et al., 2015; Moncada et al., 2011; Montano et al., 2014; Walters, 2011). Qualitative data has revealed difficulties in this area for the Swiss labour inspectors. Some expressed a wish for more training in order to better involve employees, especially in cases where the employer does not inform the staff about the visit, or when he or she is too present during the inspection. The regulatory arrangements for worker participation in Switzerland are rather limited and there are fewer work councils than in most EU countries (Teoh et al., 2013). Besides, participation was only a marginal issue in the programme theory underlying the campaign. However, a few cantonal inspectorates successfully employ participatory inspection techniques; exploring how this could be propagated in the context of Switzerland's liberal labour market seems a useful avenue of reflection. This could be interesting for other countries as well, since several studies have reported on a lack of contact between inspectors and workers (MacEachen et al., 2016; Stadler and Splittgerber, 2014).

Other analyses - not detailed in this article - found no effect of inspection on the level of employee exposure to psychosocial risk factors, as perceived by the survey respondents. A priori, inspection visits could have led to an increased awareness of risk factors or to their actual reduction, but the results did not reveal any tendency. Qualitative analyses showed that the inspectors seldom addressed psychosocial issues in terms of risk factors. For example, requiring a risk assessment that includes psychosocial dimensions remains rare. This might be an explanation for the lack of statistically significant relationships between inspection and risk perception.

Finally, two categories of workplaces notably demonstrated few improvements. On the one hand, the uninspected firms from the secondary sector with less than 100 employees felt little concern for PSRs at baseline; these workplaces were not a target of the inspection campaign and represented a small fraction of the sample. On the other hand, the uninspected large tertiary workplaces showed improvement only in their perceived ability in PSR prevention. The comparison with their inspected counterparts is a clear argument in favour of inspection effectiveness. Also interesting is the fact that larger companies from the secondary sector showed improvements, even when not inspected, thus reflecting other influences than the regulatory visits. It is well known that the bigger the company, the more resources it can invest in a structured approach to health and safety (EU-OSHA, 2016; Hasle et al., 2014; Pinder et al., 2016). This result may also be attributable to the dissemination of information by the government, the media, and various stakeholders during the campaign. 
This study has apparently been the first (quasi-)experimental investigation of the effects of labour inspection on the prevention of PSRs. The participation rate was high and the design permitted some preliminary causal interpretations. The large number of questions made a nuanced assessment possible, by differentiating between several outcome dimensions. The one-year interval between the two surveys might have been too short for the intervention to attain its full effects; on the other hand, it limited the attrition rate. Only one person was interviewed in each company; it was a manager in almost $90 \%$ of cases. In the first ESENER survey, both a manager and a health and safety representative were interviewed whenever possible. Responses were very significantly correlated for some questions and less so for other ones. Several clues suggested that managers' responses were somewhat more objective (EU-OSHA, 2012a). In the second ESENER survey, only one interview was conducted, with "the person most knowledgeable about health and safety in the establishment". Since this choice was meant to improve the quality of the information collected (EU-OSHA, 2016), the same way of proceeding was used in this study.

A random assignment of the firms between the inspected and the non-inspected groups was not feasible, since the planning of visits is a prerogative of the cantonal labour inspectorates. Indeed, at baseline, the inspected companies showed slight differences to the non-inspected ones. This probably indicates some selection effect; we controlled for it by including the scores from the first survey in the regression models. During their basic training on psychosocial issues, inspectors were actually advised to start the campaign with not too difficult cases. At any rate, in a realistic evaluation approach, it is interesting to note that the inspected firms were somewhat better beforehand: This element of context may contribute to explain why the predominantly enlightenment-based inspection visits yielded positive outcomes. Further studies could pursue this matter by specifically addressing more reluctant workplaces.

\section{Conclusion}

The rather positive results of this study should encourage inspectorates to further engage in the prevention of PSRs, since it takes time for an inspection to have an impact (Bruhn, 2006, 2009; Hansen et al., 2015; Lippel and Quinlan, 2011; Starheim and Bøgehus Rasmussen, 2014). At the end of its inspection campaign on the psychosocial working environment, the European Committee of Senior Labour Inspectors (SLIC, 2012) recommended a strategy including education, challenge, advice and partnership. We believe that stronger forms of enforcement should not be ruled out. For instance, the judgement by the Swiss Federal Court that popularised the use of confidential persons for conflicts at work was rendered after an inspectorate imposed this measure on a company. According to a systematic review by Tompa et al. (2016), there is strong evidence of an effect of inspection with penalties on OHS enforcement. These authors recommended regulators to heighten awareness by actively communicating the consequences of non-compliance. They also suggested that counselling without deterrence might be interpreted by organisations as an absence of consequence for non-compliance. The widespread "enlightenment" approach might be appropriate to foster capacity building in an initial learning phase. In the long run, it should perhaps evolve towards a more balanced strategy mix.

Finally, regulatory initiatives should emphasise the need for a prevention approach grounded in the assessment and improvement of job designs, content and organisation. Indeed, PSRs are related to employee perceptions of working conditions such as an imbalance between efforts and rewards, high demands or low levels of control (Karasek and Theorell, 1990; Siegrist, 2007). Exploring to what extent inspection visits could influence such dimensions would be a challenging avenue of reflection for policy-makers and researchers. 
Table 2

Robust regression models. DV: scores from 2nd survey. IV: scores from 1st survey and interaction terms inspection visit*sector*size.

\begin{tabular}{|c|c|c|c|c|c|c|}
\hline & \multicolumn{6}{|c|}{ Scores from 2nd survey (scales graduated 0-12) } \\
\hline & $\begin{array}{l}\text { Model } 1 \text { OHS } \\
\text { management }\end{array}$ & $\begin{array}{l}\text { Model } 2 \text { Worker } \\
\text { participation }\end{array}$ & $\begin{array}{l}\text { Model } 3 \\
\text { Willing-ness }\end{array}$ & $\begin{array}{l}\text { Model } 4 \text { PSR } \\
\text { mgmt }\end{array}$ & $\begin{array}{l}\text { Model } 5 \text { Improvement } \\
\text { working conditions }\end{array}$ & $\begin{array}{l}\text { Model } 6 \text { Compe- } \\
\text { tencies }\end{array}$ \\
\hline \multicolumn{7}{|l|}{ Scores from 1st survey } \\
\hline OHS management & $\begin{array}{l}.63^{k * * *} \\
(.05)\end{array}$ & & & & & \\
\hline Worker participation & & $\begin{array}{l}.69^{* * * *} \\
(.05)\end{array}$ & & & & \\
\hline Willingness to prevent PSRs & & & $\begin{array}{l}.53^{* * * *} \\
(.04)\end{array}$ & & & \\
\hline Specific PSR management & & & & $\begin{array}{l}.72^{* * *} \\
(.05)\end{array}$ & & \\
\hline Improvement of working conditions & & & & & $\begin{array}{l}.51^{* * \times * *} \\
(.05)\end{array}$ & \\
\hline Ability in PSR prevention & & & & & & $\begin{array}{l}.64^{* * *} \\
(.05)\end{array}$ \\
\hline \multicolumn{7}{|l|}{ Interaction terms } \\
\hline $\mathrm{NI} /$ tertiary/100+ & $\begin{array}{l}.65 \\
(.38)\end{array}$ & $\begin{array}{l}.29 \\
(.38)\end{array}$ & $\begin{array}{l}.42 \\
(.38)\end{array}$ & $\begin{array}{l}.81 \\
(.49)\end{array}$ & $\begin{array}{l}.13 \\
(.46)\end{array}$ & $\begin{array}{l}1.22^{* * *} \\
(.40)\end{array}$ \\
\hline $\mathrm{NI} /$ secondary/ < 100 & $\begin{array}{l}.91^{*} \\
(.40)\end{array}$ & $\begin{array}{l}-.46 \\
(.50)\end{array}$ & $\begin{array}{l}-1.46^{* k} \\
(.53)\end{array}$ & $\begin{array}{l}-.32 \\
(.45)\end{array}$ & $\begin{array}{l}-1.10 \\
(.62)\end{array}$ & $\begin{array}{l}-.36 \\
(.54)\end{array}$ \\
\hline $\mathrm{NI} /$ secondary/100+ & $\begin{array}{l}1.79^{* * * \times k} \\
(.41)\end{array}$ & $\begin{array}{l}1.49^{* * *} \\
(.51)\end{array}$ & $\begin{array}{l}.01 \\
(.41)\end{array}$ & $\begin{array}{l}1.08^{*} \\
(.48)\end{array}$ & $\begin{array}{l}-.05 \\
(.66)\end{array}$ & $\begin{array}{l}.38 \\
(1.29)\end{array}$ \\
\hline I/tertiary $/<100$ & $\begin{array}{l}2.02^{\text {**k* }} \\
(.37)\end{array}$ & $\begin{array}{l}.08 \\
(.37)\end{array}$ & $\begin{array}{l}.96^{* * *} \\
(.33)\end{array}$ & $\begin{array}{l}.73 \\
(.43)\end{array}$ & $\begin{array}{l}.18 \\
(.41)\end{array}$ & $\begin{array}{l}1.53^{* * k * k} \\
(.42)\end{array}$ \\
\hline I/tertiary/100+ & $\begin{array}{l}1.61^{\text {*3.ke }} \\
(.33)\end{array}$ & $\begin{array}{l}.81^{*} \\
(.38)\end{array}$ & $\begin{array}{l}1.05^{\text {k*k* }} \\
(.30)\end{array}$ & $\begin{array}{l}1.36^{* * *} \\
(.50)\end{array}$ & $\begin{array}{l}.70 \\
(.39)\end{array}$ & $\begin{array}{l}2.28^{* k * * *} \\
(.40)\end{array}$ \\
\hline I/secondary/ < 100 & $\begin{array}{l}1.90^{* * *} \\
(.41)\end{array}$ & $\begin{array}{l}.61 \\
(.57)\end{array}$ & $\begin{array}{l}.94 \\
(.54)\end{array}$ & $\begin{array}{l}-.39 \\
(.51)\end{array}$ & $\begin{array}{l}.60 \\
(.71)\end{array}$ & $\begin{array}{l}1.35^{*} \\
(.67)\end{array}$ \\
\hline $\mathrm{I} /$ secondary/100+ & $\begin{array}{l}1.86^{k \times k+k} \\
(.41)\end{array}$ & $\begin{array}{l}.70 \\
(.57)\end{array}$ & $\begin{array}{l}1.15 \\
(.80)\end{array}$ & $\begin{array}{l}1.32 \\
(.94)\end{array}$ & $\begin{array}{l}.70 \\
(.83)\end{array}$ & $\begin{array}{l}1.70^{*} \\
(.72)\end{array}$ \\
\hline Intercept & $\begin{array}{l}2.66^{\text {*.*kx }} \\
(.41)\end{array}$ & $\begin{array}{l}2.31^{\text {k*k }} \\
(.34)\end{array}$ & $\begin{array}{l}4.23^{\text {t.k.k }} \\
(.49)\end{array}$ & $\begin{array}{l}1.75^{\text {*.*kx }} \\
(.34)\end{array}$ & $\begin{array}{l}3.84^{* * * *} \\
(.52)\end{array}$ & $\begin{array}{l}1.33^{* * * * *} \\
(.30)\end{array}$ \\
\hline Robust $\mathrm{R}_{\mathrm{w}}^{2}$ & .75 & .63 & .58 & .77 & .37 & .65 \\
\hline
\end{tabular}

No. of observations: 346. Standard errors are reported in parentheses. ${ }^{*} \mathrm{p}<.05,{ }^{* *} \mathrm{p}<.01,{ }^{* * *} \mathrm{p}<.001$.

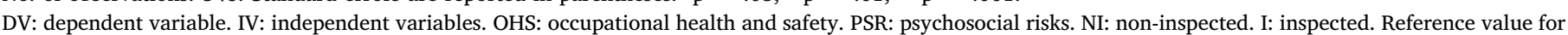
interaction terms: NI/tertiary/ $<100$.

\section{Author contributions}

RW: Lead author; participation in the design of the study; acquisition, analysis and interpretation of data; drafting of the manuscript.

MA: Participation in the design of the study; critical revision.

MG: Study design; critical revision.

SI: Participation in the design of the study; participation in data analysis; critical revision.

DG: Participation in the analysis and interpretation of data; critical revision.

\section{Acknowledgements}

This study was funded by the State Secretariat for Economic Affairs and the Federal Coordination Commission for Occupational Safety, Switzerland. We are very grateful to every company and labour inspector who took part in the study, and to our colleagues in the SECO, particularly Stephanie Lauterburg Spori, Margot Vanis, Pascal Richoz and Fabrice Sauthier. We also would like to thank our invaluable interviewers Tarek Ben Jemia, Marc Huber and Christine Villaret d'Anna, and the anonymous reviewers for their insightful comments and suggestions.

\section{Declarations of interest}

None.

\section{References}

Bøgehus Rasmussen, M., Hansen, T., Nielsen, K.T., 2011. New tools and strategies for the inspection of the psychosocial working environment: the experience of the Danish Working Environment Authority. Saf. Sci. 49 (4), 565-574. https://doi.org/10.1016/ j.ssci.2010.06.002.

Bourbonnais, R., Brisson, C., Vézina, M., 2011. Long-term effects of an intervention on psychosocial work factors among healthcare professionals in a hospital setting. Occup. Environ. Med. 68 (7), 479-486. https://doi.org/10.1136/oem.2010.055202.

Bruhn, A., 2006. The inspector's dilemma under regulated self-regulation. Policy Practice Health Safety 4 (2), 3-23. https://doi.org/10.1080/14774003.2006.11667679.

Bruhn, A., 2009. Occupational unity or diversity in a changing work context? The case of Swedish labour inspectors. Policy Practice Health Safety 7 (2), 31-50. https://doi. org/10.1080/14774003.2009.11667733.

Bruhn, A., Frick, K., 2011. Why it was so difficult to develop new methods to inspect work organization and psychosocial risks in Sweden. Saf. Sci. 49 (4), 575-581. https://doi. org/10.1016/j.ssci.2010.07.011.

Cox, T., Griffiths, A., Randall, R., 2003. A risk management approach to the prevention of work stress. In: Schabracq, M., Winnubst, J., Cooper, C. (Eds.), The Handbook of Work and Health Psychology. John Wiley \& Sons Ltd, Chichester, pp. 191-206.

Dollard, M.F., Neser, D.Y., 2013. Worker health is good for the economy: Union density and psychosocial safety climate as determinants of country differences in worker health and productivity in 31 European countries. Soc. Sci. Med. 92, 114-123. https://doi.org/10.1016/j.socscimed.2013.04.028.

EU-OSHA, 2012a. Management of occupational safety and health: An analysis of the findings of the European Survey of Enterprises on New and Emerging Risks (ESENER) - Technical report annexes 1 and 2. Luxembourg: Publications Office of the European Union. < https://osha.europa.eu/en/tools-and-publications/publications/reports/ esener_management_annexes/view $>$ (20.11.2017).

EU-OSHA, 2012b. Management of psychosocial risks at work: An analysis of the findings of the European Survey of Enterprises on New and Emerging Risks (ESENER). Luxembourg: Publications Office of the European Union. < https://osha.europa.eu/ en/node/6748/file_view > (27.01.2017).

EU-OSHA, 2016. Second European Survey of Enterprises on New and Emerging Risks (ESENER-2): Overview Report: Managing Safety and Health at Work. Luxembourg: Publications Office of the European Union. https://osha.europa.eu/en/tools-andpublications/publications/second-european-survey-enterprises-new-and-emerging- 
risks-esener (27.01.2017).

Frick, K., 2014. The 50/50 implementation of Sweden's mandatory systematic work environment management. Policy Practice Health Safety 12 (2), 23-46. https://doi.org/ 10.1080/14774003.2014.11667802.

Hansen, T., Lidsmoes, L.C., Laursen, P., Mathiassen, L., Jensen, A.-M., Suhr Raby, C., Sorensen, L., Jurvelius, H., Rintala, J., Hardarson, S., Sveinsdóttir, P., Rosenberg Sovik, S., Hjorth, B., Schyberg, P., Tiborn, M., 2015. Psychosocial working environment: Workplace Inspection of the psychosocial working environment in the Nordic countries. Nordic Council of Ministers, Copenhagen. < http://norden.diva-portal. org/smash/get/diva2:795004/FULLTEXT01.pdf > (14.10.2017).

Harris, P.A., Taylor, R., Thielke, R., Payne, J., Gonzalez, N., Conde, J.G., 2009. Research electronic data capture (REDCap)-A metadata-driven methodology and workflow process for providing translational research informatics support. J. Biomed. Inform. 42 (2), 377-381. https://doi.org/10.1016/j.jbi.2008.08.010.

Hasle, P., Limborg, H.J., Nielsen, K.T., 2014. Working environment interventions Bridging the gap between policy instruments and practice. Saf. Sci. 68, 73-80. https://doi.org/10.1016/j.ssci.2014.02.014.

Hosmer, D.W., Lemeshow, S., Sturdivant, R.X., 2013. Applied Logistic Regression. John Wiley \& Sons, Hoboken, New Jersey.

Jain, A.K., 2011. Development and implementation of policies for the management of psychosocial risks: exploring the role of stakeholders and the translation of policy into practice in Europe. University of Nottingham. < http://eprints.nottingham.ac uk/12295/2/Aditya_Jain_Thesis.pdf $>$ (1.11.2016).

Jann, B., 2010. ROBREG: Stata module providing robust regression estimators. Statistical Software Components S457114. Boston College Department of Economics.

Jespersen, A.H., Hasle, P., Nielsen, K.T., 2016. The wicked character of psychosocial risks: implications for regulation. Nordic J. Work. Life Studies 6 (3), 23-42. https://doi. org/10.19154/njwls.v6i3.5526.

Johnstone, R., Quinlan, M., McNamara, M., 2011. OHS inspectors and psychosocial risk factors: evidence from Australia. Saf. Sci. 49 (4), 547-557. https://doi.org/10.1016/ j.ssci.2010.09.016.

Karasek, R., Theorell, T., 1990. Healthy work: Stress, Productivity and the Reconstruction of Working Life. Basic Books, New York.

Kompier, M., 2004. Does the 'Management Standards' approach meet the standard? Work and Stress 18 (2), 137-139. https://doi.org/10.1080/02678370412331291434.

Kompier, M., Aust, B., 2016. Organizational stress management interventions: Is it the singer not the song? Scand. J. Work Environ. Health 42 (5), 355-358. https://doi org $/ 10.5271 /$ sjweh.3578.

Landry, A., 2008. The evaluation of ergonomic intervention: from evaluation research to proposing tools for practicing (L'évaluation de l'intervention ergonomique: de la recherche évaluative à la proposition d'outils pour la pratique). Université Victor Segalen - Bordeaux II, Bordeaux. < https://tel.archives-ouvertes.fr/tel-00363373> (12.10.2017)

Langenhan, M.K., Leka, S., Jain, A., 2013. Psychosocial risks: is risk management strategic enough in business and policy making? Safety Health Work 4, 87-94. https://doi. org/10.1016/j.shaw.2013.04.003.

Leka, S., Jain, A., Iavicoli, S., Vartia, M., Ertel, M., 2011. The role of policy for the management of psychosocial risks at the workplace in the European Union. Saf. Sci. 49, 558-564. https://doi.org/10.1016/j.ssci.2010.02.002.

Leka, S., Jain, A., Iavicoli, S., Di Tecco, C., 2015a. An evaluation of the policy context on psychosocial risks and mental health in the workplace in the European Union: achievements, challenges, and the future. BioMed. Res. Int. 2015. https://doi.org/10. $1155 / 2015 / 213089$.

Leka, S., Van Wassenhove, W., Jain, A., 2015b. Is psychosocial risk prevention possible? Deconstructing common presumptions. Saf. Sci. 71, 61-67. https://doi.org/10.1016/ j.ssci.2014.03.014.

Lindblom, L., Hansson, S.O., 2004. Evaluating workplace inspections. Policy Practice Health Safety 2 (2), 77-91. https://doi.org/10.1080/14774003.2004.11667651.

Lippel, K., Quinlan, M., 2011. Regulation of psychosocial risk factors at work: an international overview. Saf. Sci. 49 (4), 543-546. https://doi.org/10.1016/j.ssci.2010.09. 015.

MacEachen, E., Kosny, A., Stahl, C., O’Hagan, F., Redgrift, L., Sanford, S., Carrasco, C., Tompa, E., Mahood, Q., 2016. Systematic review of qualitative literature on occupational health and safety legislation and regulatory enforcement planning and implementation. Scand J Work Environ Health 42 (1), 3-16. https://doi.org/10.5271/ sjweh.3529.

Mellor, N., Mackay, C., Packham, C., Jones, R., Palferman, D., Webster, S., Kelly, P., 2011. 'Management Standards' and work-related stress in Great Britain: progress on their implementation. Saf. Sci. 49 (7), 1040-1046. https://doi.org/10.1016/j.ssci.2011. 01.010

Moncada, S., Llorens, C., Moreno, N., Rodrigo, F., Landsbergis, P., 2011. CC.OO. ("Comisiones Obreras") - ISTAS (Union Institute of Work, Environment and Health) participatory action plan for a healthier work organization: a case study. Saf. Sci. 49 (4), 591-598. https://doi.org/10.1016/j.ssci.2010.03.014.

Montano, D., Hoven, H., Siegrist, J., 2014. Effects of organisational-level interventions at work on employees' health: a systematic review. BMC Public Health 14 (1), 1-9. https://doi.org/10.1186/1471-2458-14-135.

Pawson, R., 2006. Evidence-Based Policy: A Realist Perspective. SAGE Publications Ltd, Thousand Oaks CA.

Pawson, R., Manzano-Santaella, A., 2012. A realist diagnostic workshop. Evaluation 18 (2), 176-191.

Petit, J., Dugué, B., 2012. Psychosocial risks: acting upon the organisation by ergonomic intervention. Work 41, 4843-4847. https://doi.org/10.3233/WOR-2012-0774-4843.

Pinder, J., Gibb, A., Dainty, A., Jones, W., Fray, M., Hartley, R., Cheyne, A., Finneran, A., Glover, J., Haslam, R., Morgan, J., Waterson, P., Gosling, E.Y., Bust, P., Pink, S., 2016. Occupational safety and health and smaller organisations: research challenges and opportunities. Policy Practice Health Safety 14 (1), 34-49. https://doi.org/10. 1080/14773996.2016.1239357.

Quinlan, M., Johnstone, R., McNamara, M., 2009. Australian Health and Safety Inspectors' Perceptions and Actions in Relation to Changed Work Arrangements. J. Indus. Relations 51 (4), 557-573. https://doi.org/10.1177/0022185609339519.

Renaud, O., Victoria-Feser, M.-P., 2010. A robust coefficient of determination for regression. J. Statist. Plan. Inference 140 (7), 1852-1862. https://doi.org/10.1016/j jspi.2010.01.008.

Robson, L.S., Clarke, J.A., Cullen, K., Bielecky, A., Severin, C., Bigelow, P.L., Irvin, E. Culyer, A., Mahood, Q., 2007. The effectiveness of occupational health and safety management system interventions: a systematic review. Saf. Sci. 45 (3), 329-353. https://doi.org/10.1016/j.ssci.2006.07.003.

Robson, L.S., Shannon, H.S., Goldenhar, L.M., Hale, A.R., 2001. Guide to evaluating the effectiveness of strategies for preventing work injuries. National Institute for Occupational Safety and Health, Cincinnati. < https://www.cdc.gov/niosh/docs/ 2001-119/pdfs/2001-119.pdf>

Saksvik, P.Ø., Tvedt, S.D., Nytrø, K., Andersen, G.R., Andersen, T.K., Buvik, M.P., Torvatn, H., 2007. Developing criteria for healthy organizational change. Work \& Stress 21 (3), 243-263. https://doi.org/10.1080/02678370701685707.

Shannon, H.S., Robson, L.S., Guastello, S.J., 1999. Methodological criteria for evaluating occupational safety intervention research. Saf. Sci. 31 (2), 161-179. https://doi.org/ 10.1016/S0925-7535(98)00063-0.

Siegrist, J., 2007. Effort-reward imbalance model. In: Fink, G. (Ed.), Encyclopedia of Stress, second ed. Academic Press, New York, pp. 893-896.

SLIC, 2012. Psychosocial risk assessments: SLIC Inspection Campaign 2012. Final report. The Committee of Senior Labour Inspectors. < https://circabc.europa.eu/webdav/ CircaBC/empl/SLIC\%20(public\%20access)/Library/08.\%20SLIC\%20Campaigns/ 2012 Campaign\%20on\%20psychosocial\%20risks\%20at\%20work/Psychosocial \%20risks\%20Campaign_Final\%20report.pdf > (14.10.2017).

Stadler, P., Splittgerber, B., 2014. Psychosocial Risks at Work - an inspection campaign of the German labour authorities. ASU International 7. https://doi.org/10.17147/ASUI. 2014-07-04-01.

Starheim, L., Bøgehus Rasmussen, M., 2014. Labour inspection strategies addressing the psychosocial work environment. Policy Practice Health Safety 12 (1), 53-70. https:// doi.org/10.1080/14774003.2014.11667797.

StataCorp, 2015. Stata Statistical Software: Release 14. College Station, TX: StataCorp LP.

Teoh, K., Hassard, J., Cox, T., 2013. Worker participation - Switzerland. < https:// oshwiki.eu/wiki/Worker participation - Switzerland > (20.11.2017).

Tompa, E., Kalcevich, C., Foley, M., McLeod, C., Hogg-Johnson, S., Cullen, K., MacEachen, E., Mahood, Q., Irvin, E., 2016. A systematic literature review of the effectiveness of occupational health and safety regulatory enforcement. Am. J. Ind. Med. 59 (11), 919-933. https://doi.org/10.1002/ajim.22605.

Toukas, D., Delichas, M., Toufekoula, C., Spyrouli, A., 2015. The role of labour inspectorates in tackling the psychosocial risks at work in Europe: problems and perspectives. Safety Health Work 6 (4), 263-267. https://doi.org/10.1016/j.shaw.2015. 06.001 .

Walters, D., 2004. Workplace arrangements for worker participation in OHS. In: Buff, E. Gunningham, N., Johnstone, R. (Eds.), OHS Regulation for a Changing World of Work. The Federation Press, Sydney, pp. 68-93.

Walters, D., 2011. Worker representation and psycho-social risks: a problematic relationship? Saf. Sci. 49 (4), 599-606. https://doi.org/10.1016/j.ssci.2010.09.008.

Walters, D., Johnstone, R., Frick, K., Quinlan, M., Baril-Gingras, G., Thébaud-Mony, A. 2011. Regulating Workplace Risks: A Comparative Study of Inspection Regimes in Times of Change. Edward Elgar Publishing, Cheltenham, UK.

Weil, D., 2008. A strategic approach to labour inspection. Int. Lab. Rev. 147 (4), 349-375. https://doi.org/10.1111/j.1564-913X.2008.00040.x.

Weissbrodt, R., Arial, M., Graf, M., Ben Jemia, T., Villaret D’Anna, Ch., Giauque, D., 2018. Preventing psychosocial risks: a study of employers' perceptions and practices (Prévenir les risques psychosociaux : une étude des perceptions et des pratiques des employeurs). Relations Industrielles/Industrial Relations 73 (1), 174-203.

Weissbrodt, R., Giauque, D., 2017. Labour inspections and the prevention of psychosocial risks at work: a realist synthesis. Saf. Sci. 100, 110-124. https://doi.org/10.1016/j. ssci.2017.02.012.

Zoni, S., Lucchini, R., 2012. European approaches to work-related stress: a critical review on risk evaluation. Safety Health Work 3 (1), 43-49. https://doi.org/10.5491/SHAW. 2012.3.1.43. 